\title{
Formation and thermo-assisted stabilization of luminescent silver clusters in photosensitive glasses
}

\author{
Kevin Bourhis ${ }^{\mathrm{a}, *}$, Arnaud Royon ${ }^{\mathrm{b}}$, Gautier Papon ${ }^{\mathrm{b}}$, Matthieu Bellec ${ }^{\mathrm{b}}$, Yannick Petit ${ }^{\mathrm{a}}$, Lionel Canioni ${ }^{\mathrm{b}}$, \\ Marc Dussauze $^{c}$, Vincent Rodriguez ${ }^{c}$, Laurent Binet ${ }^{\mathrm{d}}$, Daniel Caurant ${ }^{\mathrm{d}}$, Mona Treguer $^{\mathrm{a}}$, \\ Jean-Jacques Videau ${ }^{\mathrm{a}}$, Thierry Cardinal ${ }^{\mathrm{a}}$ \\ ${ }^{a}$ CNRS, University Bordeaux, ICMCB, UPR 9048, F-33600 Pessac, France \\ ${ }^{\mathrm{b}}$ University Bordeaux, LOMA, UMR 5798, F-33405 Talence, France \\ ${ }^{\mathrm{c}}$ University Bordeaux, ISM, UMR 5798, F-33405 Talence, France \\ ${ }^{\mathrm{d}}$ ENSCP (Chimie-ParisTech), LCMCP, UMR CNRS 7574, 11 rue Pierre et Marie, F-75231 Paris cedex 05, France
}

A R T I C L E I N F O

Keywords:

A. Optical materials

B. Electronic paramagnetic resonance (EPR)

B. Luminescence

D. Color centers

D. Optical properties

\begin{abstract}
A B S T R A C T
Various photo induced silver luminescent centres were obtained in photosensitive zinc and phosphate glasses containing silver ions after exposure to gamma or ultraviolet nanosecond pulsed laser radiation. Gamma irradiation of the glasses results mainly in the formation within the glass of electron trapped and hole trapped silver centres as evidenced by optical absorption, luminescence and electron spin resonance spectroscopies. For the highest irradiation doses silver clusters are obtained. Under ultraviolet nanosecond pulsed laser exposure similar species are generated along the beam propagation direction as proven by the analogous optical and luminescence signatures. In this case for high irradiation doses few silver clusters are created. The evolution of the luminescence spectra with respect to the temperature and to the duration of the heat treatment after ultraviolet nanosecond pulsed laser irradiation evidences the presence of potential barriers determining the stability limits of some species such as the $\mathrm{Ag}^{2+}$ hole trapped centres or the $\mathrm{Ag}_{\mathrm{m}}{ }^{\mathrm{x}}$ clusters composed of silver ions and silver atoms. A heat treatment of several hundreds of degrees is identified as a the key parameter for tailoring the optical properties and controlling the formation of $\mathrm{Ag}_{\mathrm{m}}{ }^{{ }^{+}}$clusters in the photosensitive glasses.
\end{abstract}

\section{Introduction}

The photostructuring of materials consists in taking advantage of their photosensitivity to allow a local modification of the material. The main goal is the elaboration of active photonic devices [1]. Short pulsed lasers have been demonstrated since the late 1990s to be powerful tools allowing surface and bulk modification of glassy material [2]. Choosing the right laser irradiation parameters enables three dimensional (3D) processing of the glassy matrix. For example, Glezer et al. used femtosecond (fs) laser photo modification in fused silica for 3D data storage application [3]. Picosecond and femtosecond lasers are considered to be "athermal" since the pulse width is much shorter than the time of heat diffusion in glasses, typically $1 \mu \mathrm{s}$ in fused silica for a beam waist of $2 \mu \mathrm{m}[4,5]$. However when processing at a high repetition rate, in the order of magnitude of the $\mathrm{MHz}$, the absorbed energy cannot be dissipated, resulting in thermal accumulation pulse after pulse. Eaton and co workers reported that when

\footnotetext{
* Corresponding author. Tel.: +33 540002543; fax: +33 540002761.

E-mail address: bourhis@icmcb-bordeaux.cnrs.fr (K. Bourhis).
}

operating with a fs laser at repetition rates from $100 \mathrm{kHz}$ to $1 \mathrm{MHz}$, the temperature elevation was estimated to be equal to several thousands of Celsius degrees [6]. Heat accumulation by fs laser irradiation at a high repetition rate $(>100 \mathrm{kHz})$ has been recog nized as a useful effect for the processing of glasses in recent years [7 11]. For example, optical waveguides with symmetric guiding cross sections can be formed by isotropic thermal diffusion [7]. Heat accumulation inside a glass also induces the precipitation of crystals [10] or the modification of the chemical composition distribution around the laser focal volume $[11,12]$, which make possible to control the three dimensional properties in glasses.

Recently our group showed that irradiating photosensitive glasses containing silver ions using an IR fs laser operating at a high repetition rate resulted in the formation of fluorescent pipes within the glass without any significant variation of the refractive index $\left(\Delta n<10^{4}\right)$ [13]. The section of the pipes consists in a ring structure composed of luminescent silver clusters [14]. Its formation was explained by a three step mechanism: (i) photo ionization; (ii) thermal diffusion and (iii) photo dissociation. The proposed model for the fluorescent ring shaped formation strongly suggested that thermal effects were mostly responsible of the spatial distribution of the silver clusters and of their 
luminescence during the laser irradiation [13]. Bellec et al. evidenced that the luminescence intensity of the structures, suspected to be related to the aggregation of the silver clusters, could be tailored on a large intensity scale by controlling the near IR fs laser parameters [15]. An accurate control of the lumines cence intensity at the mesoscopic scale was achieved. Mastering the aggregation of the silver atoms and their optical properties in photosensitive materials opens the way to applications for perennial high density data storage. Appealing approaches have recently been demonstrated in glasses where the photolumines cence of laser induced silver clusters [16] or the wavelength and polarization dependence of laser elongated silver nanoparticles [17] were used for the data readout. The shape of the luminescence spectra was however dependent on the irradiation conditions, leaving some uncertainties on the nature of the photo induced species. Moreover the influence of the temperature on the formation and on the stability of the photo induced silver species was not debated. The major difficulty is to separate the thermal effects from the photo ionization mechanisms related to the laser energy absorption.

The optical signatures of the luminescence spectra of such glasses after gamma, electron and nanosecond laser irradiations attributed to silver hole and electron centres and clusters, present very strong analogies with the ones obtained after femtosecond laser irradiation [14,18]. In this paper an experimental step by step approach is developed. The different phenomena (photo ionization and thermal effects) are studied separately to allow a progressive comprehension of the mechanisms and to try to identify the different photo produced species. First, gamma irradiations at the scale of the bulk glasses were performed. The occurring mechanism is mainly the formation of electron and hole centres within the whole bulk material. Second, a UV nanosecond pulsed laser operating at a low repetition rate was used for the irradiations. This kind of exposure favours the formation of electron hole pairs, while minimizing the thermal effects. The interaction area is reduced to a cylinder with millimetric section, related to the size of the laser beam, along the thickness of the vitreous sample. Third, heat treatments (HT) are carried out subsequently to the UV laser irradiation, in order to add insights on the thermal effects on the nature and on the concentration of the photo induced species.

\section{Experimental}

\subsection{Glass elaboration and preparation}

Glasses with the composition $40 \mathrm{P}_{2} \mathrm{O}_{5} 55 \mathrm{ZnO} \quad 1 \mathrm{Ga}_{2} \mathrm{O}_{3} \quad 4 \mathrm{Ag}_{2} \mathrm{O}$ (mol\%) were prepared by melt quenching. $\left(\mathrm{NH}_{4}\right)_{2} \mathrm{HPO}_{4}, \mathrm{ZnO}$, $\mathrm{AgNO}_{3}$ and $\mathrm{Ga}_{2} \mathrm{O}_{3}$ in powder form were used as raw materials and mixed together with the appropriate amount in a platinum crucible. A heating rate of $1{ }^{\circ} \mathrm{C}$ min ${ }^{1}$ was conducted up to $1000^{\circ} \mathrm{C}$. The melt was then kept at this last temperature $\left(1000^{\circ} \mathrm{C}\right)$ from 24 to $48 \mathrm{~h}$. Following this step, the liquid was poured into a brass mould after a short increase of the temperature at $1100{ }^{\circ} \mathrm{C}$ in order to access the appropriate viscosity. The glass samples obtained were annealed at $320^{\circ} \mathrm{C}\left(40{ }^{\circ} \mathrm{C}\right.$ below the glass transition temperature) for $3 \mathrm{~h}$, cut ( $0.51 \mathrm{~mm}$ thick) and optically polished. The optical properties of the pristine glass were described elsewhere [14].

\subsection{Gamma irradiation}

Gamma irradiations were performed at room temperature using a ${ }^{137} \mathrm{Cs}$ source delivering doses from $0.18 \mathrm{kGy}$ to $5.4 \mathrm{kGy}$ at a dose rate of $0.36 \mathrm{kGy} \mathrm{h}{ }^{1}$.

\subsection{UV nanosecond laser irradiation}

A mode locked Nd:YAG laser (Surelite Continuum L10) pumped by flash lamps was used at room temperature. It was equipped with BBO nonlinear crystals to obtain the $355 \mathrm{~nm}$ output wavelength. The pulse duration was $5 \mathrm{~ns}$ at a $10 \mathrm{~Hz}$ repetition rate for a $80 \mathrm{~mJ}$ pulse energy. The beam diameter on the glass sample was $5 \mathrm{~mm}$. The fluence was $400 \mathrm{~mJ} \mathrm{~cm}{ }^{2}$ and the irradiance $67 \mathrm{MW} \mathrm{cm}^{2}$.

\subsection{Absorption spectroscopy}

The transmission spectra were recorded at room temperature with a Varian Cary 5000 spectrophotometer in double beam configuration between $200 \mathrm{~nm}$ and $800 \mathrm{~nm}$ with a $1 \mathrm{~nm}$ step and a $2 \mathrm{~nm}$ spectral bandwidth. The transmission spectra were corrected from the Fresnel reflection and from the glass thickness.

\subsection{Luminescence spectroscopy}

The macroscopic luminescence spectra (emission and excita tion) on the gamma and UV irradiated glasses were recorded at room temperature with a SPEX Fluorolog 2 spectrofluorimeter (Horiba Jobin Yvon). The excitation source was a $450 \mathrm{~W}$ xenon lamp enabling continuous excitation from $200 \mathrm{~nm}$ to $800 \mathrm{~nm}$. The signal was detected and amplified by a Hamamatsu R298 photomultiplier.

Fluorescence lifetimes were measured at room temperature with two setups. For lifetimes higher than $10 \mu$ s the measure ments were performed with a SPEX Fluorolog 2 spectrofluo rimeter (Horiba Jobin Yvon) with double monochromators both in excitation and emission in the Czerny Turner configuration. The excitation source was a pulsed xenon lamp emitting pulses of $3 \mu \mathrm{s}$ full width at half maximum (FWHM). The signal was detected and amplified by a Hamamatsu R298 photomultiplier. The temporal resolution was about $2 \mu \mathrm{s}$. The lifetimes between $50 \mathrm{~ns}$ and $10 \mu \mathrm{s}$ were measured with a Nd:YAG laser (Surelite) emitting pulses of $57 \mathrm{~ns}$ FWHM at $355 \mathrm{~nm}$. The diameter of the beam on the sample was of $1 \mathrm{~mm}$ for a deposited energy of $0.4 \mathrm{~nJ} /$ pulse corresponding to a $320 \mathrm{~kW} \mathrm{~cm}^{2}$ irradiance. The emitted fluorescence was collimated by lenses and injected in an optical fibre. At the fibre output the light was diffracted by a MS260i spectrometer (Oriel) equipped with a pair of gratings in the Czerny Turner configuration and analyzed by a ICCD iStar 720 camera (Andor Technology). The temporal resolution was about $10 \mathrm{~ns}$.

\subsection{Electron paramagnetic resonance (EPR) spectroscopy}

The EPR spectra were recorded at room temperature with a Bruker Elexsys E500 spectrometer operating at $\mathrm{X}$ band at $9.45 \mathrm{GHz}$ and equipped with a SHQ resonator. A $100 \mathrm{kHz}$ modulation of the magnetic field was used for lock in detection, so that the EPR signals appear as absorption derivatives with respect to the magnetic field. A few milligrams of glass powder were necessary. No influence of the temperature (down to $15 \mathrm{~K}$ ) on the shape of the signals after irradiations was observed, indicating that the paramagnetic centres observed are stabilized at room temperature.

\section{Results}

All the experiments were performed at room temperature. The irradiated glass samples were not studied immediately after irradiation and/or heat treatment, which means that the transitory phosphate and silver species could not be observed $[19,20]$. 

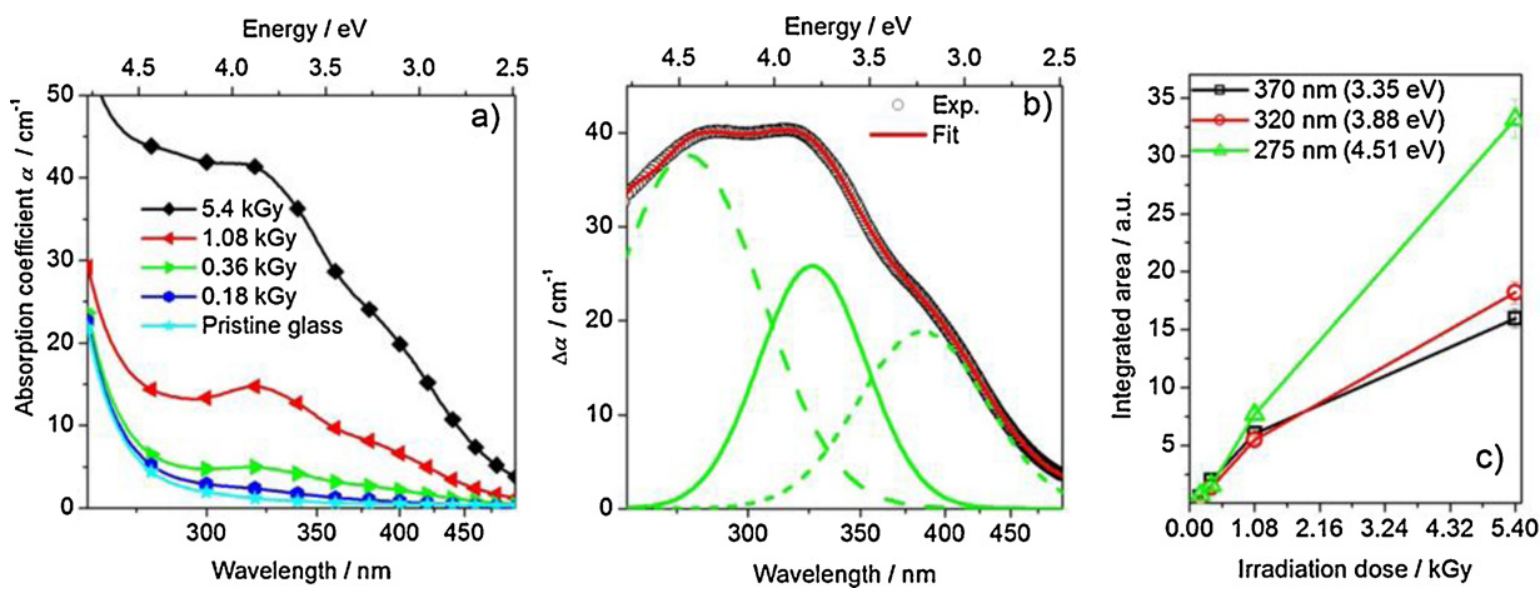

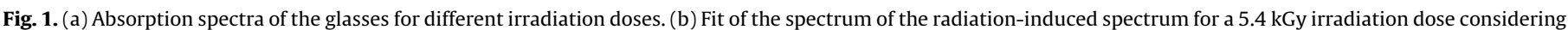

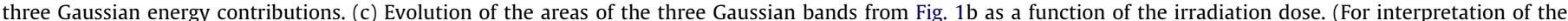
references to colour in this figure legend, the reader is referred to the web version of this article.)

\subsection{Gamma irradiation induced centres and optical signatures}

The absorption spectra of the glasses after gamma irradiation are presented in Fig. 1a. The photo induced absorption bands appear in the spectral domain between $200 \mathrm{~nm}$ and $500 \mathrm{~nm}$. Several bands are visible around $275 \mathrm{~nm}, 320 \mathrm{~nm}$ and $370 \mathrm{~nm}$. Their intensity increases with the irradiation dose. The radiation induced spectra (that is the difference between the spectra after and before irradiation) were fitted considering Gaussian energy contributions for the photo induced species, as shown in Fig. 1b for the $5.4 \mathrm{kGy}$ irradiated glass. Fig. 1c shows the evolution of the integrated areas of the three Gaussian bands used for the fit. The assignment of those bands is not an easy task. According to the literature, the band at $320 \mathrm{~nm}$ was ascribed to the $\mathrm{Ag}^{2+}$ or $\mathrm{Ag}_{3}{ }^{2+}$ silver species and the band at around $370 \mathrm{~nm}$ to $\mathrm{Ag}^{0}$ atoms in various gamma irradiated glass matrices [21 24]. Ershov et al. determined the theoretical absorption characteristics of different silver clusters, defined as $\mathrm{Ag}_{m}{ }^{x+}$ clusters, where $m$ is the number of ions and atoms and $x$ the formal charge [25]. They calculated that the $\mathrm{Ag}^{2+}$ species have absorption features at around $310320 \mathrm{~nm}$ and $360400 \mathrm{~nm}$ and that the $\mathrm{Ag}_{3}{ }^{2+}$ clusters exhibit intense absorption bands near $260285 \mathrm{~nm}$ and $540720 \mathrm{~nm}$ and a lower one at $275320 \mathrm{~nm}$. The calculated position of the absorption bands of clusters with a low nuclearity are in accordance with the experimental observations. As shown in Fig. 1c, the area of the band at $275 \mathrm{~nm}$ shows a nearly linear fast increase with the irradiation dose. An inflexion of the slopes for the bands at $320 \mathrm{~nm}$ and $370 \mathrm{~nm}$, when the irradiation dose increases is observed. Such behaviour may be related to a slowing down of the formation reactions of the different species or a consumption of these species. For example the recombination kinetics of the electrons with the silver ions or the diffusion of $\mathrm{Ag}^{+}$and $\mathrm{Ag}^{0}$ atoms to form the $\mathrm{Ag}_{2}{ }^{+}$ are susceptible to be the key factors having an influence on the resulting absorption spectrum.

To better understand the species formed after irradiation, EPR spectroscopy was performed. The EPR spectra of the glasses before and after gamma irradiation are represented in Fig. 2a. Before irradiation, no EPR transition is visible, indicating that no paramagnetic centres are observed within the detection limit. From the lowest irradiation doses, several signals are observed. They are similar to those recently measured by Fan et al. in a vitreous system whose composition is close to ours $\left(\mathrm{P}_{2} \mathrm{O}_{5} \mathrm{Li}_{2} \mathrm{O}\right.$ $\mathrm{Al}_{2} \mathrm{O}_{3} \mathrm{Ag}_{2} \mathrm{O}$ ) [24]. Several signals corresponding to different species (electron and hole centres) are observed on the spectrum of the glass submitted to a $5.4 \mathrm{kGy}$ irradiation. The transitions at $3045 \mathrm{G}$ and $3675 \mathrm{G}$ are assigned to a $\mathrm{Ag}^{0}$ centre (electron centre) $[19,24,27]$. This centre is characterized by a two line signal owing to the hyperfine coupling with ${ }^{107} \mathrm{Ag}(I=1 / 2$, natural abundance
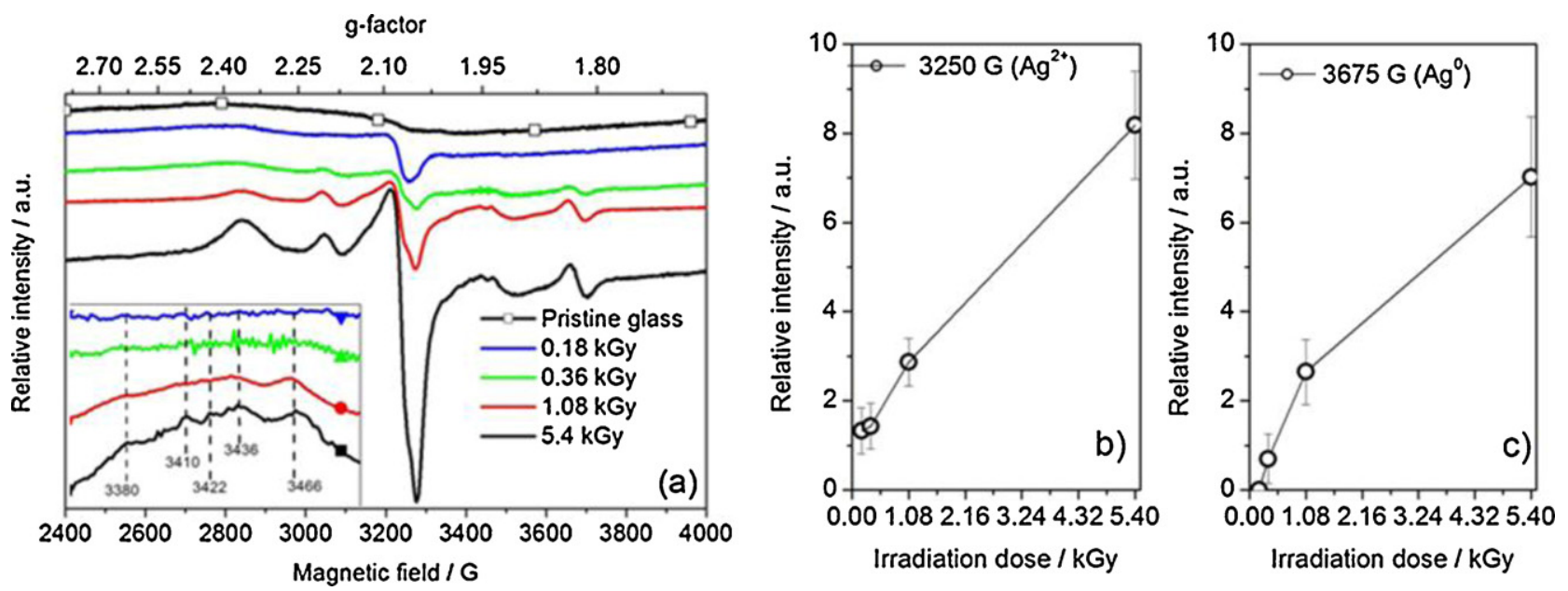

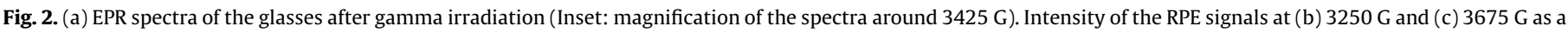
function of the irradiation dose. (For interpretation of the references to colour in this figure legend, the reader is referred to the web version of this article.) 
$51.8 \%)$ and ${ }^{109} \mathrm{Ag}$ nuclei $(I=1 / 2$, natural abundance $48.2 \%)$. For each hyperfine line, the splitting due to the two isotopes of the $\mathrm{Ag}$ nucleus is not resolved. This spectrum is similar in shape to the one observed by Yokota and Imawaga after stabilization of the $\mathrm{Ag}^{0}$ centre at room temperature [19]. Since the unpaired electron is mainly in an $\mathrm{s}$ type orbital $\left(5 \mathrm{~s}^{1}\right.$ configuration for $\left.\mathrm{Ag}^{0}\right)$, the $\mathrm{g}$ factor and the hyperfine interaction are both dominantly isotropic. The values determined by simulation of the spectrum obtained after irradiation at $5.4 \mathrm{kGy}$ are: $g_{\text {iso }}=1.965$ for the $g$ factor and $A_{\text {iso }}=550 \mathrm{G}$ for the average hyperfine coupling for ${ }^{107} \mathrm{Ag}$ and ${ }^{109} \mathrm{Ag}$. The transitions at $2840 \mathrm{G}$ and $3250 \mathrm{G}$ correspond to the parallel component $g_{\|} \approx 2.36$ and the perpendicular component $g_{\perp} \approx 2.06$ of an $\mathrm{Ag}^{2+}$ ion (hole centre) in an axial symmetry as already reported by several authors [19,24,27]. It is interesting to note that the phosphorous oxygen hole centre (POHC), whose formation is reported in literature after $\mathrm{X}$ or gamma irradiation of phosphate glasses [20,27 29], was not detected in our irradiated samples. This centre is associated to an intense EPR signal with a $g$ factor close to 2.008 and $A_{\text {iso }}=4 \mathrm{G}$ [20]. The absence of this centre at room temperature in our irradiated glass samples can be explained by the fact that, according to the literature, the POHC centre is stable at room temperature after $\mathrm{X}$ or gamma irradiation of phosphate glasses (i) that do not contain $\mathrm{Ag}_{2} \mathrm{O}[20,26]$ and (ii) that contain $\mathrm{Ag}_{2} \mathrm{O}$ and that are moderately depolymerised (i.e. phosphate glasses with $\mathrm{O} / \mathrm{P} \leq 3$ ) [26]. In our case, the phosphate network is too depolymerised $(\mathrm{O} / \mathrm{P}=3.275>3)$ to enable the formation of stable POHC and only the more stable $\mathrm{Ag}^{2+}$ hole centres are detected at room temperature. It is also interesting to point out that, because of the occurrence of $\mathrm{Ag}_{2} \mathrm{O}$ in our glasses, phosphate electron centres are not detected after irradiation [18] and only the most efficient $\mathrm{Ag}^{0}$ electron centres are detected.

To evaluate the change in the amounts of the $\mathrm{Ag}^{0}$ and $\mathrm{Ag}^{2+}$ centres with the irradiation dose, the intensities of the perpendic ular component at $3250 \mathrm{G}$ of the $\mathrm{Ag}^{2+}$ centre and the intensity of the high field hyperfine line at $3675 \mathrm{G}$ of the $\mathrm{Ag}^{0}$ centre were measured. The intensities of these lines were approximated by Eq. (1) [30].

$I \propto Y_{\max } \times\left(\Delta H_{\mathrm{pp}}\right)^{2}$

where $Y_{\max }$ is the peak to peak amplitude of the line and $\Delta H_{\mathrm{pp}}$ the peak to peak linewidth.

The intensity of the signals at $3250 \mathrm{G}$ and $3675 \mathrm{G}$ are reported in Fig. $2 b$ and $c$ as a function of the irradiation dose. The intensity of the $3250 \mathrm{G}$ line, attributed to the $\mathrm{Ag}^{2+}$ hole centres, increases with the irradiation dose. It is difficult in accordance with the error bars to conclude between a linear or a nonlinear evolution. Regarding the evolution of the intensity of the line at $3675 \mathrm{G}$, associated to $\mathrm{Ag}^{0}$ electron centres, the situation is clearer. The intensity strongly increases up to $1.08 \mathrm{kGy}$ and has a lower slope from $1.08 \mathrm{kGy}$ to $5.4 \mathrm{kGy}$. The growth of the EPR signal intensity at $3675 \mathrm{G}$ versus the irradiation doses is comparable to the one observed for the $370 \mathrm{~nm}$ optical absorption band areas (Fig. 1c), which was also attributed to $\mathrm{Ag}^{0}$ atoms. The slope break observed in both cases for the same irradiation dose ( $1.08 \mathrm{kGy}$ ) may indicate the consump tion of $\mathrm{Ag}^{\mathrm{O}}$ atoms and their clustering at the highest irradiation doses. The intensity of the transition associated to the $\mathrm{Ag}^{2+}$ centre at $3250 \mathrm{G}$ increases by a factor 4 after a $5.4 \mathrm{kGy}$ irradiation dose compared to a $0.18 \mathrm{kGy}$ irradiation dose. This is the same behaviour as for the increase of the optical absorption band at $370 \mathrm{~nm}$ and $320 \mathrm{~nm}$. For higher doses, additional EPR signals are observed in the $33003600 \mathrm{G}$ magnetic field range, as shown by the inset in Fig. 2a. These signals are generally assigned to $\mathrm{Ag}_{m}{ }^{x^{+}}$ $(x<m)$ clusters with a low nuclearity [19,27,31]. Their absence from the EPR spectra of the glasses after irradiation at $0.18 \mathrm{kGy}$ and $0.36 \mathrm{kGy}$ seems to indicate that, for these irradiation doses, the amount of $\mathrm{Ag}^{0}$ locally generated is not sufficient to allow a significant formation of $\mathrm{Ag}_{m}{ }^{x+}$ clusters.

The normalized excitation $\left(\lambda_{\mathrm{em}}=700 \mathrm{~nm}\right)$ and emission $\left(\lambda_{\text {exc }}=325 \mathrm{~nm}\right)$ spectra of the irradiated glasses are represented in Fig. 3a. The emission maximum of the irradiated glasses is located at $\lambda=630 \mathrm{~nm}$ and is accompanied by a band near $500 \mathrm{~nm}$. The intensity of both bands increases with the irradiation dose. The intensities of the different contributions to the emission is dependent on the excitation wavelength. Indeed for a $405 \mathrm{~nm}$ excitation wavelength, the emission band at around $500 \mathrm{~nm}$ becomes predominant (not shown here). The excitation spectra for the $0.18 \mathrm{kGy}$ and $5.4 \mathrm{kGy}$ doses are represented in Fig. 3b for $\lambda_{\text {em }}=700 \mathrm{~nm}$. The selection of the $700 \mathrm{~nm}$ emission wavelength allows to minimize the pristine glass contribution which has an emission spectrum ranging from $350 \mathrm{~nm}$ to $600 \mathrm{~nm}$ for an excitation wavelength at around $260 \mathrm{~nm}[13,14]$. Several excita tion bands are visible between $250 \mathrm{~nm}$ and $500 \mathrm{~nm}$. An intense broadband is observed near $320 \mathrm{~nm}$ for the $0.18 \mathrm{kGy}$ irradiated glass. It is accompanied by shoulders at $275 \mathrm{~nm}$ and $370 \mathrm{~nm}$. The excitation spectra can be decomposed by the three Gaussian bands already identified in the absorption spectra at $370 \mathrm{~nm}, 320 \mathrm{~nm}$ and $275 \mathrm{~nm}$ respectively. The intensity of the bands increases with the irradiation dose. The fit of the luminescence decay curves for an excitation at $325 \mathrm{~nm}$ and an emission at $700 \mathrm{~nm}$ (Fig. 3c) by a
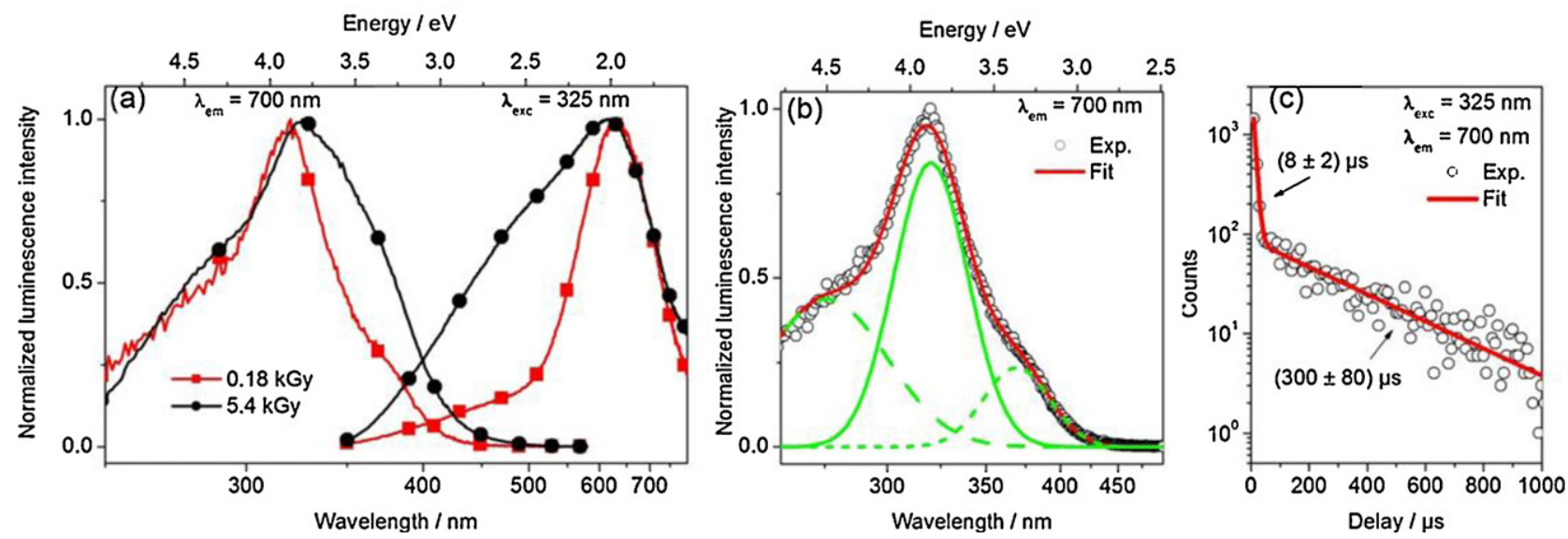

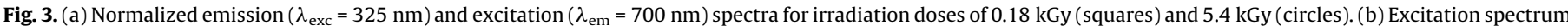

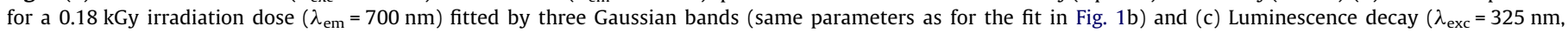

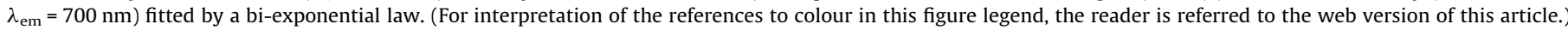


bi exponential law gives lifetimes equals to $\tau_{1}=(8 \pm 2) \mu \mathrm{s}$ and $\tau_{2}=(300 \pm 80) \mu \mathrm{s}$. The $\tau_{1}$ lifetime is observed in all the fitted decays for excitation wavelengths varying from $325 \mathrm{~nm}$ to $405 \mathrm{~nm}$ and emission wavelength included between $400 \mathrm{~nm}$ and $700 \mathrm{~nm}$. The $\tau_{2}$ lifetime, much longer, is most probably associated to $\mathrm{Ag}^{+} \mathrm{Ag}^{+}$pairs already present in low quantity in the pristine glass [33]. Indeed a luminescence lifetime of $125 \mu$ s was already measured in unirradi ated glasses with similar composition by Belharouak et al. [32]. It was attributed to silver dimers $\left(\mathrm{Ag}^{+} \mathrm{Ag}^{+}\right)$after comparison with silver polyphosphate crystals in which the $\mathrm{X}$ ray diffraction data indicated some pairing of silver ions in neighbouring cells [33]. For these glasses a broad emission band peaking near $550 \mathrm{~nm}$ for an excitation wavelength at around $325 \mathrm{~nm}$ was observed. It is reasonable to assume that this band contributes to the one observed in our case near $500 \mathrm{~nm}$. However the increase of its intensity and the measured lifetime cannot be explained by the unique presence of the silver dimer centres reported by Belkarouak et al. Regarding the shorter $\tau_{1}$ lifetime, luminescence lifetimes ranging from $1 \mu$ s to $30 \mu$ s were previously reported in silver activated radiophotoluminescent glasses after gamma exposure [34]. Such lifetimes are hardly compatible with the emission of silver clusters which are considered to present shorter lifetimes on the order of a few nanoseconds or less $[15,3538]$. Therefore, we propose that the $\tau_{1}$ lifetime of a few microseconds is attributed to the emission of the $\mathrm{Ag}^{2+}$ species. Such assignment for the $630 \mathrm{~nm}$ emission band was already proposed by Hsu et al. [39].

In conclusion for the gamma irradiation study, two main photo induced centres were identified $\left(\mathrm{Ag}^{0}\right.$ and $\left.\mathrm{Ag}^{2+}\right)$ and the presence of $\mathrm{Ag}_{m}{ }^{x+}$ species $(x<m)$ in low quantity was strongly suggested. The luminescence measurements concluded on the presence of several emitting centres. The emission band near $630 \mathrm{~nm}$ is associated to the excitation band near $325 \mathrm{~nm}$ and the lifetime of $8 \mu \mathrm{s}$ is most probably related to a $\mathrm{d} d$ transition of the $\mathrm{Ag}^{2+}$ ion. One can suppose that the excitation band near $325 \mathrm{~nm}$ is not unique and additional bands may be possible near $275 \mathrm{~nm}$ or $370 \mathrm{~nm}$, corresponding to the $3 \mathrm{~d}$ orbital splitting. For the high irradiation doses additional absorption bands are observed near $280 \mathrm{~nm}$, $320 \mathrm{~nm}$ and $350 \mathrm{~nm}$ (Fig. 1a) which may be related to the formation of $\mathrm{Ag}_{m}{ }^{x+}$ clusters.

\subsection{Identification of the species induced by UV nanosecond laser irradiation}

The absorption spectra of the glasses before and after irradiation by 10 180,000 pulses are shown in Fig. 4a. After 10 pulses, a small variation of the absorption coefficient is observed in the $270550 \mathrm{~nm}$ spectral range. Two shoulders are visible near
$325 \mathrm{~nm}$ and $380 \mathrm{~nm}$. Their intensities strongly increase when the number of pulses reaches several thousands. Below $300 \mathrm{~nm}$ the spectrum of the 10 pulses irradiated glass is less intense than that of the pristine glass one. This "negative" difference may signify a local consumption of the local $\mathrm{Ag}^{+}$ions (absorbing below $300 \mathrm{~nm}$ ). When increasing the number of pulses, the difference between the spectra of the irradiated glasses and the pristine glass decreases until it becomes "positive". This observation means that absorbing species are generated, which might be related to the optically absorbing silver clusters (near $290 \mathrm{~nm}$ ), also detected by EPR spectroscopy after gamma irradiation (Figs. 1a and 2a). EPR investigation on the UV laser irradiated glass samples was not successful due to the small irradiated volume limiting the amount of UV produced species. Indeed in the case of gamma irradiation the whole glass is exposed to the beam which eases the detection of photo produced species. For UV laser irradiations, the exposed zone is reduced to a cylindrical area along the $5 \mathrm{~mm}$ diameter beam path. The photo produced clusters are believed to be much less numerous since the absorption coefficient after 180,000 pulses (Fig. 4a) is still 10 times lower than the one of the $5.4 \mathrm{kGy}$ irradiation dose (Fig. 1a), for which the EPR spectroscopy allows the detection of magnetic signatures attributed to silver clusters (Fig. 2a) The emission spectra of the UV laser irradiated glasses are represented in Fig. 4b for a $325 \mathrm{~nm}$ excitation wavelength. The spectra are dominated by an intense band centred at about $630 \mathrm{~nm}$, attributed to $\mathrm{Ag}^{2+}$ species by Hsu and co workers [39]. For 10 pulses, the $630 \mathrm{~nm}$ band is unique. The signal observed for wavelengths below $500 \mathrm{~nm}$ arises from background noise due to the very low intensity of the emission signal combined with emission of the pristine glass [32]. For several thousands of pulses, the $630 \mathrm{~nm}$ band intensity strongly increases and another weak band is observed near $450 \mathrm{~nm}$, similarly to those observed in the case of gamma irradiation (Fig. 3a). The corresponding excitation spectrum for a $700 \mathrm{~nm}$ emission wavelength is shown in Fig. 4b. For 10 pulses two bands near $275 \mathrm{~nm}$ and $320 \mathrm{~nm}$ are observed with a shoulder of low intensity around $370 \mathrm{~nm}$. When the number of pulses increases, the relative intensity of the $320 \mathrm{~nm}$ and $370 \mathrm{~nm}$ strongly rises whereas the contribution below $275 \mathrm{~nm}$ band decreases. This last band was attributed to the free $\mathrm{Ag}^{+}$ion exhibiting an excitation band maximum at around $265 \mathrm{~nm}$ and an emission band maximum at around $380 \mathrm{~nm}$ in the pristine glass [14]. Its contribution is significant for low numbers of pulses because the tail of the emission of the free $\mathrm{Ag}^{+}$ion extends up to $750 \mathrm{~nm}$. Its relative intensity decreases with the number of pulses since the intensities of the emission bands of the photo produced species near $320 \mathrm{~nm}$ and $370 \mathrm{~nm}$ become dominant. The fit of the excitation spectra with the same Gaussian energy distribution
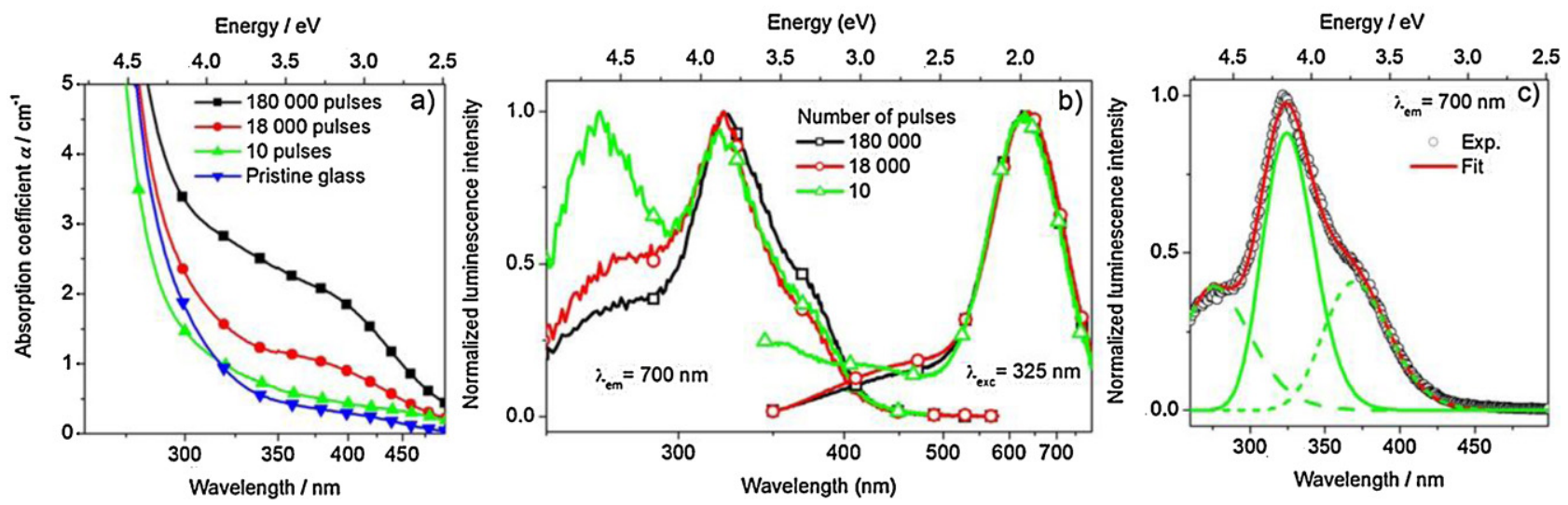

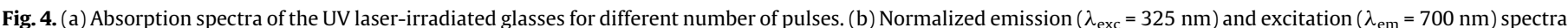

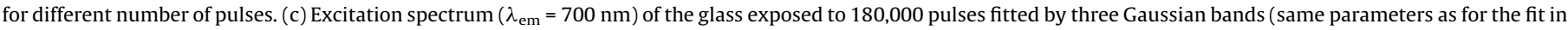
Fig. 1b). (For interpretation of the references to colour in this figure legend, the reader is referred to the web version of this article.) 

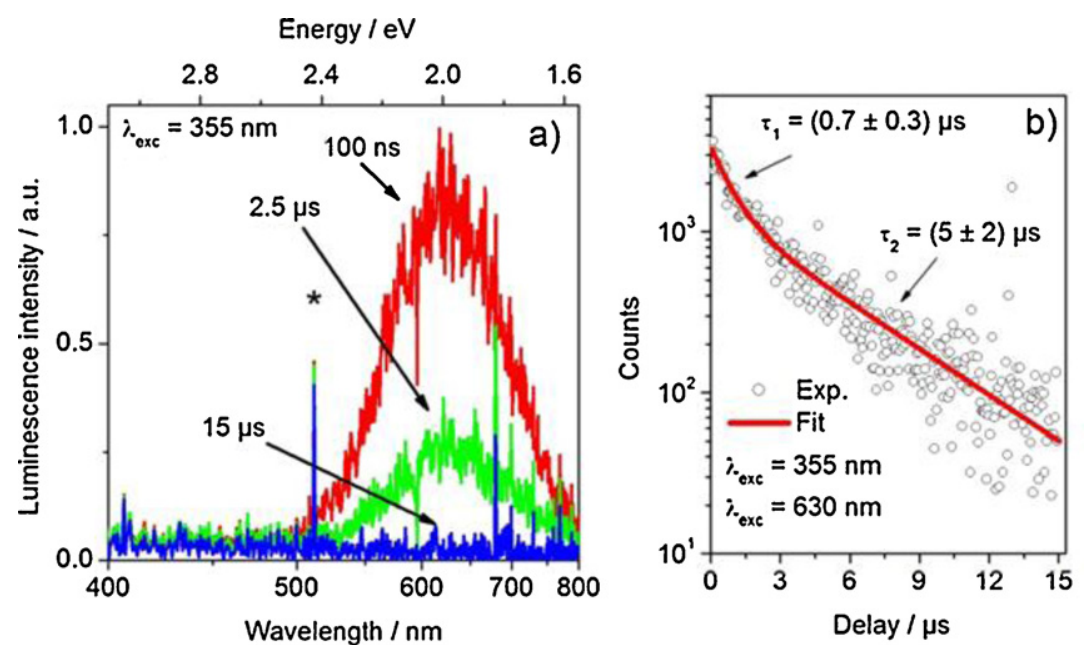

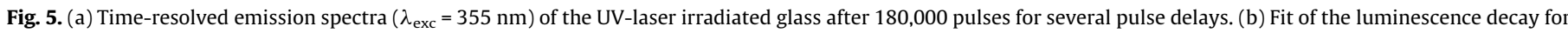

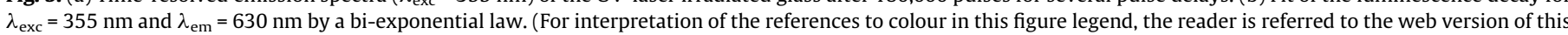
article.)

parameters as in the case of the gamma irradiation was successful, as demonstrated in Fig. 4c for a UV laser irradiation of 180,000 pulses. The bands at $320 \mathrm{~nm}$ and $370 \mathrm{~nm}$ seem to be linked together and an excitation at these wavelengths leads to a unique emission band at $630 \mathrm{~nm}$, most probably related to the $\mathrm{Ag}^{2+}$ species. The fit of the luminescence decays (not shown here) for three excitation wavelengths ( $325 \mathrm{~nm}, 355 \mathrm{~nm}$ and $405 \mathrm{~nm}$ ) and the $600 \mathrm{~nm}$ emission wavelength indicated a unique lifetime equal to $(9 \pm 3) \mu \mathrm{s}$. To detect shorter lifetimes, measurements were performed with the UV nanosecond laser as exciting pulsed source. The time resolved emission spectra of the 180,000 pulses irradiated glass is shown in Fig. 5a for different delays after the $355 \mathrm{~nm}$ excitation pulse. After a 100 ns delay, the spectrum collected shows a broadband centred near $630 \mathrm{~nm}$. For further delays, the intensity of the $630 \mathrm{~nm}$ band decreases progressively while keeping the same spectral shape. After $15 \mu \mathrm{s}$, the fluorescence signal merges to the background. The luminescence decay lifetimes were deduced by plotting the intensity of the band at $630 \mathrm{~nm}$ versus the delay after the pulse. A typical luminescence decay for $\lambda_{\text {exc }}=355 \mathrm{~nm}$ and $\lambda_{\text {em }}=630 \mathrm{~nm}$ is represented in Fig. 5b. Two lifetimes were deter mined after fitting of the decays by a bi exponential law. The first one is about $(0.7 \pm 0.3) \mu s$ and the second $(5 \pm 2) \mu s$. The longer lifetime is compatible with the ones measured previously on gamma irradiated samples and is therefore assigned to $\mathrm{Ag}^{2+}$ centres. The shorter lifetime might be related to luminescence extinction or energy transfer phenomena.

In conclusion for the UV nanosecond laser irradiation study, the excitation bands at $325 \mathrm{~nm}$ and $380 \mathrm{~nm}$ are linked to the emission band at $630 \mathrm{~nm}$ with a lifetime on the order of $5 \mu \mathrm{s}$ attributed to the $\mathrm{Ag}^{2+}$ species. The weak emission band near $500 \mathrm{~nm}$ is related mainly to an excitation band near $325 \mathrm{~nm}$ and may also arise from excitations at lower wavelengths ( $275 \mathrm{~nm})$. It is most probably related to $\mathrm{Ag}_{m}{ }^{x+}$ silver clusters with a low nuclearity as in the case of the gamma irradiation study.

\subsection{Stability and formation of the UV laser photo induced centres after heat treatment}

The evolution of the photo induced species versus HT was investigated using the UV laser irradiated samples after 18,000 pulses. Several temperatures from $200{ }^{\circ} \mathrm{C}$ up to $400{ }^{\circ} \mathrm{C}$ were applied to the UV laser irradiated glasses for different durations from $2 \mathrm{~min}$ to $10 \mathrm{~min}$. This temperature range was chosen given the numerical simulations performed by Bellec et al. [13]. Fs laser irradiation at a $10 \mathrm{MHz}$ repetition rate of a glass of the same composition as the one studied in this paper provokes a temperature increase which reaches $400{ }^{\circ} \mathrm{C}$ after $10^{4}$ pulses, supposed to be the driving force leading to the formation of stable silver clusters [15]. This temperature is reached in $1 \mathrm{~ms}$ given the high repetition rate of the laser and is most probably higher when the number of pulses increases to $10^{5} 10^{7}$. However it is not possible to proceed to long heat treatment at such a temperature, which is $20^{\circ} \mathrm{C}$ higher than the $T_{\mathrm{g}}$ of the glass, because the glass is softened and starts to undergo physical deformation beyond the $T_{\mathrm{g}}$.

The optical absorption spectra of the glasses as irradiated and after HT are presented in Fig. 6a. After 2 min of HT at $400{ }^{\circ} \mathrm{C}$,the absorption coefficient is divided by two in the 280500 spectral range. For a $10 \mathrm{~min} \mathrm{HT}$, the spectrum exhibits almost no deviation as compared to the one collected for the pristine glass, except for a shoulder distinguishable at around $320 \mathrm{~nm}$.

The emission spectra for a $325 \mathrm{~nm}$ wavelength excitation are depicted in Fig. 6b. As soon as the HT is performed, a decrease of the intensity of the global fluorescence is observed, accompanying the diminishing of the optical absorption bands as described above. A strong increase of the band near $500 \mathrm{~nm}$ is noticed. A shoulder of weak intensity is visible in the tail of the band below $400 \mathrm{~nm}$. When the duration of the HT rises, several phenomena occur. The intensity of the $630 \mathrm{~nm}$ band undergoes a strong decrease and becomes quasi negligible after $10 \mathrm{~min}$ of HT. A broadband centred at $500 \mathrm{~nm}$ dominates the whole spectrum. The shoulder observed below $400 \mathrm{~nm}$ is strongly amplified and exhibits a maximum near $380 \mathrm{~nm}$. Its intensity becomes equal to that of the $500 \mathrm{~nm}$ band. The excitation spectra for a $700 \mathrm{~nm}$ emission wavelength for samples heat treated at $400{ }^{\circ} \mathrm{C}$ are shown in Fig. 6b. As announced previously, the photo induced absorption and emission intensities decrease after heat treating the samples. For comparison, the spectra were normalized in Fig. 6b. The fit of the different excitation spectra was conducted using Gaussian energy con tributions peaking respectively at $370 \mathrm{~nm}, 320 \mathrm{~nm}$ and $275 \mathrm{~nm}$, like for gamma and UV laser irradiations, as shown in Fig. 6c. For a $2 \mathrm{~min}$ HT, the intensity of the bands at $320 \mathrm{~nm}$ and $370 \mathrm{~nm}$ decreases while a band at around $275 \mathrm{~nm}$ grows in relative intensity. For a $10 \mathrm{~min} \mathrm{HT}$, this band dominates the spectrum while the contribution at $370 \mathrm{~nm}$ has completely disappeared. The band at $320 \mathrm{~nm}$ is still present. The luminescence decay measurements performed on the microsecond setup (Spex Fluorolog 2 Jobin Yvon) for several excitation and emission wavelengths indicate the presence of a lifetime of about 

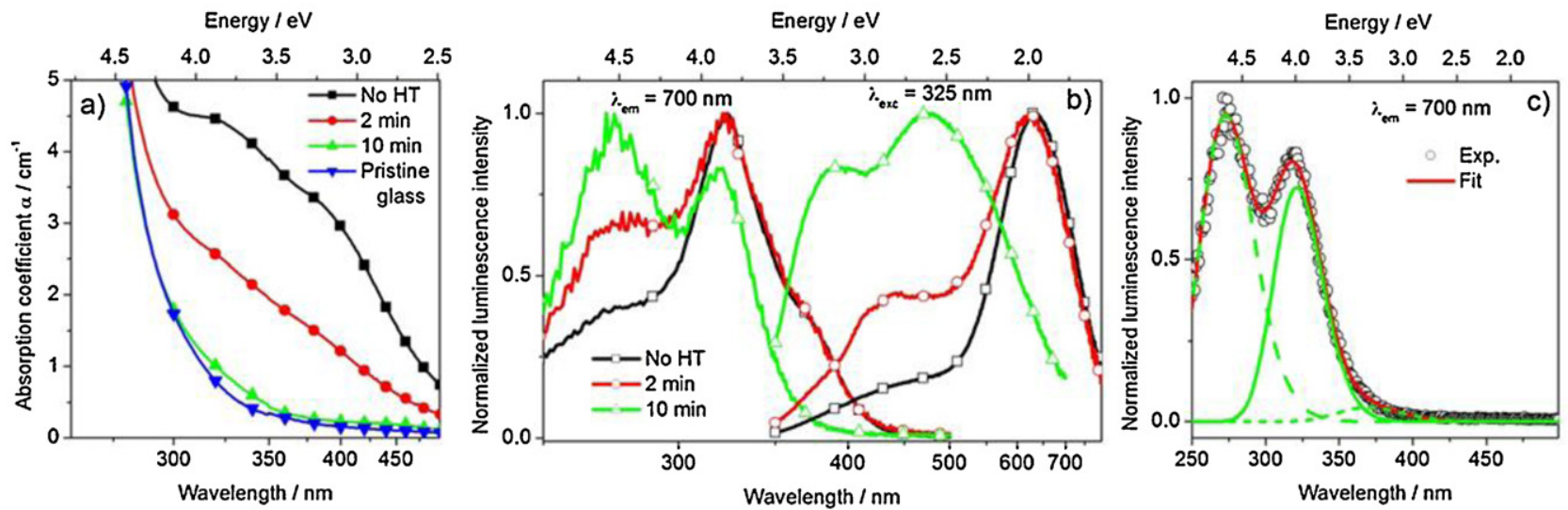

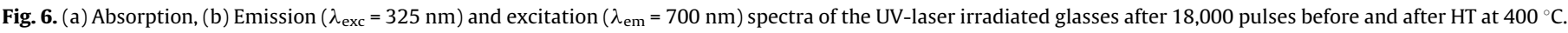

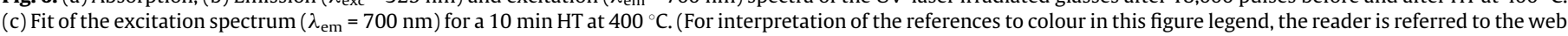
version of this article.)

$(8 \pm 3) \mu s$. No shorter lifetimes could be detected with any setup given the low density of photo induced centres and the low intensity of the associated luminescence.

The observations related to the HTs at $400{ }^{\circ} \mathrm{C}$ are representative of the tendencies observed for all the other temperatures and duration. The strong intensity decrease in the absorption spectra between $280 \mathrm{~nm}$ and $500 \mathrm{~nm}$ indicates the disappearance of most of the colour centres. The band at $380 \mathrm{~nm}$ attributed to $\mathrm{Ag}^{0}$ species is no longer visible. The luminescence spectra show that the emission band at $630 \mathrm{~nm}$ progressively decreases under heating. These data are consistent with the disappearance of the $\mathrm{Ag}^{0}$ and $\mathrm{Ag}^{2+}$ photo produced centres. The new luminescent bands at $380 \mathrm{~nm}$ and $500 \mathrm{~nm}$ for main excitation at $275 \mathrm{~nm}$ and $320 \mathrm{~nm}$ are most likely resulting in the relaxation of the electrons and holes trapped on the $\mathrm{Ag}^{\mathrm{O}}$ and $\mathrm{Ag}^{2+}$ centres. The evolution of those last bands versus the temperature is different and suggests that they arise from different emitting centres. The centre emitting at around $380 \mathrm{~nm}$ was observed only in the case of the $400{ }^{\circ} \mathrm{C}$ HT for durations on the order of $10 \mathrm{~min}$.

A temperature close to the $T_{\mathrm{g}}$ results in increasing the mobility of the species including electrons and holes but also ions. The HT is likely to overcome the potential barrier required for the formation of $\mathrm{Ag}_{m}{ }^{x+}$ silver clusters composed of both $\mathrm{Ag}^{+}$and $\mathrm{Ag}^{0}$ species. The emission band near $500 \mathrm{~nm}$ in silver containing glasses was attributed by Belharouak and co authors [32] to molecular centres whose related short lifetime on the order of the nanosecond would be linked to $5 \mathrm{~s} \leftrightarrow 5 \mathrm{p}$ allowed transitions [40]. The calculations of the optical transitions energies for some charged $\mathrm{Ag}_{m}{ }^{x+}$ clusters (with $m \leq 14$ atoms) in aqueous solution were performed by Ershov et al. [25]. Some of them exhibit several intense absorption bands between $250 \mathrm{~nm}$ and $400 \mathrm{~nm}$, especially clusters with a low nuclearity. For example for the $\mathrm{Ag}_{2}{ }^{+}$ion, the calculation shows two transitions near $310320 \mathrm{~nm}$ (s p levels) and $360400 \mathrm{~nm}$ (s s levels), for the $\mathrm{Ag}_{3}{ }^{2+}$ two transitions occur near $260285 \mathrm{~nm}$ (s p* levels) and $275320 \mathrm{~nm}$ (s s levels) and for the $\mathrm{Ag}_{4}{ }^{2+}$ two transitions near $270293 \mathrm{~nm}$ (s p* levels) and $320390 \mathrm{~nm}$ (s s levels). It is therefore strongly believed that such silver clusters may be generated during the HT process.

\section{Discussion}

Gamma and UV nanosecond laser irradiations mainly result in the formation of colour centres like the $\mathrm{Ag}^{2+}$ hole centres and the $\mathrm{Ag}^{0}$ electron centre. The absorption band at $380 \mathrm{~nm}$ was assigned to $\mathrm{Ag}^{0}$ atoms. The emission at $630 \mathrm{~nm}$ for the main excitation band around $320 \mathrm{~nm}$ was attributed to $\mathrm{Ag}^{2+}$ ions, with an associated lifetime ranging from 5 to $8 \mu \mathrm{s}$. It was shown in the case of the gamma irradiations that for the higher doses the density of photo produced centres allows the formation of weakly concentrated $\mathrm{Ag}_{m}{ }^{x+}$ silver species. Several converging proofs tend to confirm this trend in the case of UV laser irradiations, though this irradiation mode produces also mainly colour centres. For UV nanosecond laser irradiations followed by HTs, a significant production of silver clusters is observed. Such clusters are formed for temperatures ranging from $200{ }^{\circ} \mathrm{C}$ to temperatures beyond the glass transition temperature $\left(T_{\mathrm{g}}=380^{\circ} \mathrm{C}\right)$. It is probable that beyond the $T_{\mathrm{g}}$ the growth of the clusters is accelerated since the crystallization rate in glasses generally reaches a maximum for temperatures slightly superior to the $T_{\mathrm{g}}$. The presence of the $380 \mathrm{~nm}$ emission only for HTs at $400{ }^{\circ} \mathrm{C}$ means that the associated species have a high activation barrier which prevents its formation at lower tempera tures. Syutkin et al. assumed that the cluster formation was governed by the diffusion of $\mathrm{Ag}^{+}$ions [31], but requires the transfer of an electron coming from a phosphate group towards an $\mathrm{Ag}^{+}$ion to initiate the clustering reactions [41].

On the other hand, the colour centres $\left(\mathrm{Ag}^{0}\right.$ and $\left.\mathrm{Ag}^{2+}\right)$ exhibit a low thermal stability since they begin to disappear progressively from $200{ }^{\circ} \mathrm{C}$. Therefore we conclude that the trapping of the electrons and holes by these colour centres is of low energy and that their relaxation may occur as soon as their vibrational levels, whose energy is close to that of the conduction/valence band, are thermally filled. However, the silver colour centres are still more stable than the POHCs. Even if some POHCs pre exist at room temperature in the pristine phosphate glasses [20] or are generated by the UV laser irradiations, they relax due to electron transfer from the $\mathrm{Ag}^{+}$ion $[42,43]$. In our case the measurements at room temperature did not allow the characterization of such transient species, though they may be observed at low temperature $[19,20]$.

The evolution of the different silver species after laser irradiation and HT can be described by a two step mechanism (Fig. 7). The first step consists in the formation of colour centres $\left(\mathrm{Ag}^{0}\right.$ and $\left.\mathrm{Ag}^{2+}\right)$ consecutively to the formation of electron hole pairs during the laser irradiation. When the irradiation dose (i.e. the number of pulses) is high enough, the concentration of colour centres is sufficient to allow their clustering in a low quantity of $\mathrm{Ag}_{m}{ }^{x+}$ species. The second step probably combines two effects related to the relaxation of the colour centres to $\mathrm{Ag}^{+}$ions and a diffusion process of the electrons and ions inside the medium leading to the formation of the clusters. It seems also obvious that for temperatures of some hundreds of Celsius degrees, most of the "free" electron and holes recombinate. It is strongly probable that the nuclearity of the $\mathrm{Ag}_{m}{ }^{x+}$ clusters is temperature dependent, as shown by the apparition of the band near $380 \mathrm{~nm}$ in the emission spectrum. More investigations are necessary to identify the 

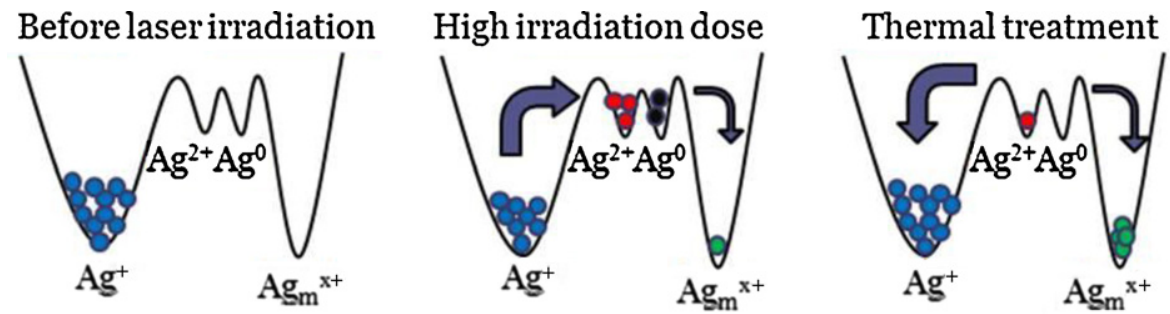

Fig. 7. Schematic representation of the evolution of the different silver species before irradiation (left), after high dose irradiation (middle) and after heat treatment (right).

relation between the colour centre density, which is linked to both the quantity of electron hole pairs generated during the irradia tion and the temperature increase, and the amount of stabilized $\mathrm{Ag}_{m}{ }^{x+}$ silver clusters.

\section{Conclusions}

The goal of this work was to study separately the effects of the photo absorption and of the temperature on the formation and consumption of silver species in photosensitive zinc and phos phate glasses containing silver ions. This study allowed the progressive comprehension of the involved mechanisms and the identification of the different photo produced species. The glasses were exposed either to gamma or to ultraviolet nanosecond pulsed laser radiations followed by a heat treatment in the case of the laser irradiation.

The gamma irradiation study has pointed out that $\mathrm{Ag}^{0}$ and $\mathrm{Ag}^{2+}$ species are formed from the very low irradiation doses. High irradiation doses are required to observe the apparition of $\mathrm{Ag}_{m}{ }^{x+}$ clusters, most probably linked to a clustering of the photo induced species when their concentration overtakes a certain concentra tion. The optical and magnetic signatures of the produced species have been identified.

The effect of a UV nanosecond laser irradiation of the photosensitive glasses has been investigated. Based on the results obtained after the gamma irradiations, it is concluded that it resulted mainly in the formation of the $\mathrm{Ag}^{0}$ and $\mathrm{Ag}^{2+}$ centres and of a small amount of $\mathrm{Ag}_{m}{ }^{{ }^{+}}$clusters.

Consecutive heat treatments ranging from $200{ }^{\circ} \mathrm{C}$ to $400{ }^{\circ} \mathrm{C}$ for durations up to 10 min lead to the conclusion that the $\mathrm{Ag}^{0}$ and $\mathrm{Ag}^{2+}$ photo induced centres have a low thermal stability. Raising the temperature resulted in a dramatic diminution of the absorption and luminescence signals related to these species, leading also probably to the recombination of most electrons and holes. It is believed that the increase of the temperature is responsible for a higher mobility of the $\mathrm{Ag}^{0}$ and $\mathrm{Ag}^{2+}$ species, resulting in their clustering.

On the basis of the results presented herein, appealing perspectives for the development of this work concern on going studies on the time resolved luminescence spectroscopy of the silver species photo induced after fs laser irradiation at the micrometric scale. In a future work, the main results presented above will be compared to the optical signatures of femtosecond laser irradiations in glasses, confirming the similar nature of the photo induced species. An improved description of the mechanism at the mesoscopic scale may also be achieved by near field scanning optical microscopy, which allows a sub wavelength resolution. In this case, the repartition of the different silver species within the focal volume could be obtained.

\section{Acknowledgements}

This work has been supported by the GIS Advanced Materials in Aquitaine", the Region Aquitaine and the ANR (grants BLAN 94603 and BLAN 946 04).

\section{References}

[1] M. Ams, G.D. Marshall, P. Dekker, J.A. Piper, M.J. Withford, Laser \& Photon Rev. 3 (2009) 535.

[2] K.M. Davis, K. Miura, N. Sugimoto, K. Hirao, Opt. Lett. 21 (1996) 1729.

[3] K.E.N. Glezer, M. Milosavljevic, L. Huang, R.J. Finlay, T.-H. Her, J.P. Callan, E. Mazur, Opt. Lett. 21 (1996) 2023.

[4] R. Gattass, E. Mazur, Nat. Photonics 2 (2008) 219.

[5] A. Royon, Y. Petit, G. Papon, M. Richardson, L. Canioni, Opt. Mat. Express 1 (2011) 866.

[6] S.M. Eaton, H. Zhang, P.R. Herman, F. Yoshino, L. Shah, J. Bovatsek, A.Y. Arai, Opt. Express 13 (2005) 4708

[7] L. Shah, A.Y. Arai, S.M. Eaton, P.R. Herman, Opt. Express 13 (2005) 1999.

[8] C.B. Schaffer, J.F. Garcia, E. Mazur, Appl. Phys. A: Mater. Sci. Process 76 (2003) 351

[9] A. Vogel, J. Noack, G. Huttman, G. Paltauf, Appl. Phys. B: Lasers Opt. 81 (2005) 1015.

[10] K. Miura, J. Qiu, T. Mitsuyu, K. Hirao, Opt. Lett. 25 (2000) 408.

[11] S. Kanehira, K. Miura, K. Hirao, Appl. Phys. Lett. 93 (2008) 023112.

[12] M. Shimizu, M. Sakakura, M. Ohnishi, Y. Shimotsuma, T. Nakaya, K. Miura, K. Hirao, J. Appl. Phys. 108 (2010) 073533.

[13] M. Bellec, A. Royon, B. Bousquet, K. Bourhis, M. Treguer, T. Cardinal, M. Richardson, L. Canioni, Opt. Express 17 (2009) 10304.

[14] K. Bourhis, A. Royon, M. Bellec, J. Choi, A. Fargues, M. Treguer, J.-J. Videau, D. Talaga, M. Richardson, T. Cardinal, L. Canioni, J. Non-Cryst. Solids 356 (2009) 2658.

[15] M. Bellec, A. Royon, K. Bourhis, J. Choi, B. Bousquet, M. Treguer, T. Cardinal, J.-J. Videau, M. Richardson, L. Canioni, J. Phys. Chem. C 114 (2010) 15584.

[16] A. Royon, K. Bourhis, M. Bellec, G. Papon, B. Bousquet, Y. Deshayes, T. Cardinal, L. Canioni, Adv. Mater. 22 (2010) 5282.

[17] A. Stalmashonak, A. Abdolvand, G. Seifert, Appl. Phys. Lett. 99 (2011) 201904.

[18] C. Maurel, T. Cardinal, M. Bellec, L. Canioni, B. Bousquet, M. Treguer, J.J. Videau, J. Choi, M. Richardson, J. Lumin. 129 (2009) 1514-1518.

[19] R. Yokota, H. Imagawa, J. Phys. Soc. Jpn. 23 (1966) 1038.

[20] P. Ebeling, D. Ehrt, M. Friedrich, Opt. Mater. 20 (2002) 101.

[21] T. Feldmann, A. Treinin, J. Chem. Phys. 47 (1967) 2754.

[22] D. Möncke, D. Ehrt, Glass Sci. Technol., 77 (2004) 239.

[23] D. Möncke, D. Ehrt, Opt. Mater. 25 (2004) 425

[24] R. Espiau de Lamaestre, H. Béa, H. Bernas, J. Belloni, J.L. Marignier, Phys. Rev. B 76 (2007) 205431.

[25] B.G. Ershov, G.V. Ionova, A.A. Kiseleva, Russ. J. Phys. Chem. 69 (1995) 239

[26] S. Fan, C. Yu, D. He, K. Li, L. Hu, Rad. Meas. 46 (2011) 46.

[27] J. Michalik, L. Kevan, J. Am. Chem. Soc. 108 (1986) 4247.

[28] D.L. Griscom, E.J. Friebele, K.J. Long, J.W. Fleming, J. Appl. Phys. 54 (1983) 3743.

[29] R. Yokota, H. Imagawa, J. Phys. Soc. Jpn. 20 (1965) 1537.

[30] J.E. Wertz, J.R. Bolton, Electron Spin Resonance: Elementary Theory and Practical Applications, McGraw-Hill, New York, 1972.

[31] V.M. Syutkin, A.B. Astashkin, A.V. Dmitryuk, Fiz. Khim. Stekla 18 (1992) 139.

[32] I. Belharouak, C. Parent, B. Tanguy, G. Le Flem, M. Couzi, J. Non-Cryst. Solids 244 (1999) 238.

[33] I. Belharouak, C. Parent, P. Gravereau, J.P. Chaminade, G. Le Flem, B. Moine, J. Solid State Chem. 149 (2000) 284.

[34] H. Schneckenburger, D.F. Regulla, E. Unsold, Appl. Phys. A 26 (1981) 23.

[35] G. De Cremer, Y. Antoku, M.B.J. Roeffaers, M. Sliwa, J. Van Noyen, S. Smout, J. Hofkens, D.E. De Vos, B.F. Sels, T. Vosch, Angew. Chem. Int. Ed. Engl. 47 (2008) 2813.

[36] G. De Cremer, E. Coutino-Gonzalez, M.B.J. Roeffaers, B. Moens, J. Ollevier, M. Van der Auweraer, R. Schoonheydt, P.A. Jacobs, F.C. De Schryver, J. Hofkens, D.E. De Vos, B.F. Sels, T. Vosch, J. Am. Chem. Soc. 131 (2009) 3049.

[37] G. De Cremer, E. Coutiño-Gonzalez, M.B.J. Roeffaers, D.E. De Vos, J. Hofkens, T. Vosch, B.F. Sels, Chem. Phys. Chem. 11 (2010) 1627.

[38] J.J. Velázquez, V.K. Tikhomirov, L.F. Chibotaru, N.T. Cuong, A.S. Kuznetsov, V.D. Rodríguez, M.T. Nguyen, V.V. Moshchalkov, Opt. Express 20 (2012) 13582.

[39] S.M. Hsu, S.W. Yung, R.K. Brow, W.L. Hsu, W.L. Chen, C.F. Ching, Mater. Chem. Phys. 123 (2010) 172.

[40] M. Mesnaoui, C. Parent, B. Tanguy, M. Maazaz, G. Le Flem, B. Moine, C. Pedrini, Adv Mater. Res. 1-2 (1994) 83.

[41] V.M. Syutkin, A.V. Dmitryuk, V.A. Tolkachev, Fiz. Khim. Stekla 18 (1992) 66.

[42] V.M. Syutkin, V.A. Tolkatchev, A.V. Dmitryuk, S.E. Paramzina, Chem. Phys. 196 (1995) 139.

[43] V.M. Syutkin, V.A. Tolkatchev, Chem. Phys. 212 (1996) 149. 